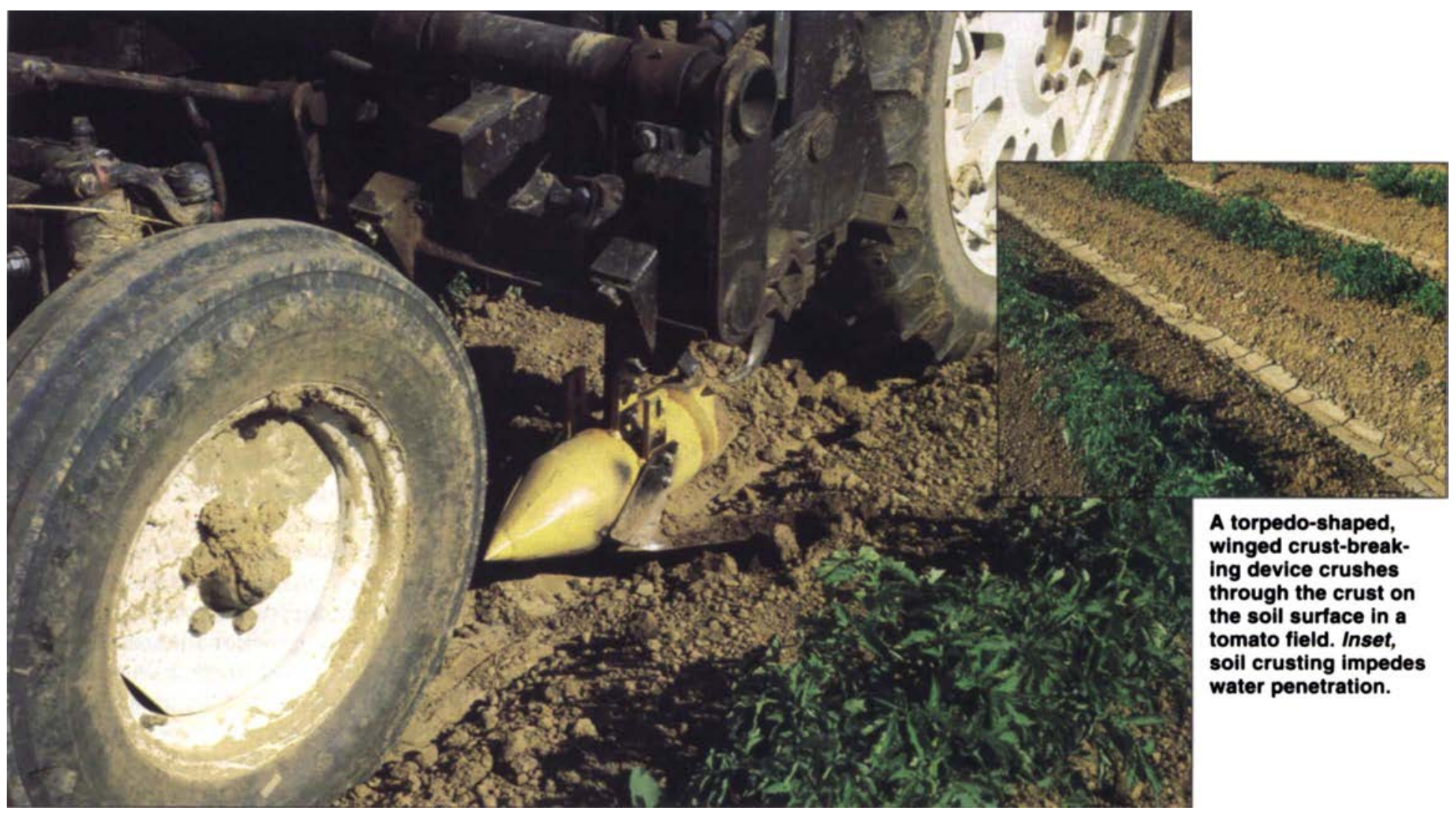

\title{
Crust-breaking device improves water infiltration into furrows
}

\author{
Shrini K. Upadhyaya $\square$ J. Jafari Far $\square$ Sayedahmad Shafii $\square$ H. Abdel Fattah
}

\section{Surface irrigation may lead to thick depositional crusts at the soil surface, which can reduce infiltration rate. To break the crust on the sides of the bed near the bottom of a furrow, we developed a torpedo-shaped, winged cultiva- tor. Field experiments were con- ducted on a tomato crop at UC Davis on Yolo loam soil during the summer of 1992. Breaking the crust with the device in- creased cumulative infiltration significantly, by almost $30 \%$.}

Electrical energy used in irrigating crops is $12 \%$ of the total energy required by California agriculture. Nearly $95 \%$ of the energy fueling irrigation pumps is supplied by electric motors, accounting for almost $68 \%$ of the direct electrical energy used by California agriculture - approximately 7 billion $\mathrm{kWh}$. About $43 \%$ of this energy is used for pumping water out of the ground, and another $31 \%$ is used for moving water from the supply source to the field. The remaining $26 \%$ is used to pressurize irrigation systems for applying water to the crop. Slow water penetration can lead to longer irrigation time to satisfy crop requirements, causing more evaporation and deep percolation while moving water from the source to the field. These losses reduce irrigation efficiency.

Soil crusting and compaction are the two major physical factors that impede water penetration into the soil. According to the 1984 Land Air and Water Resources Department report Water Penetration Problems in California
Soils, slow water penetration is a major problem in the production of crops on over 2.5 million acres, or more than $20 \%$ of the irrigated land in California. Annual dollar losses are estimated to be from $\$ 20 /$ acre in irrigated pasture to $\$ 500$ /acre in some orchards. Soils of all textures, from sandy loams to clays, have water-penetration problems.

Slow water penetration into soils has the direct effect of reducing yields if plants become water stressed due to insufficient available water. Also, conveyance loss is increased while moving the water from the source to the field, thus increasing irrigation water requirements. The problem is particularly serious in light of the increasing urban demand for water, coupled with depletion of groundwater.

Infiltration can be substantially increased if the depositional crust at the 
bottom of the furrow is broken with a crust breaker. Enhanced infiltration rate reduces irrigation time, which in turn reduces conveyance losses when moving the water from source to the field, ultimately reducing pumping energy requirements. Moreover, additional savings in labor can be achieved.

The objectives of this study were (1) to develop a crust-breaking device to destroy the depositional crust near the bottom of the furrow in a furrowirrigated field, and (2) to investigate the effect of destroying the depositional crust formed by furrow irrigation on infiltration characteristics of soil in a tomato field.

\section{Crust-breaking device}

We designed a torpedo-shaped, winged device to break the depositional crust near the bottom of the furrow on both sides. Two of the crustbreaker units were fabricated and attached to a tool bar using cultivator shanks 2 inches wide by $1 / 2$ inch thick (51 $\mathrm{mm}$ by $12 \mathrm{~mm}$ ). Right-handed and left-handed beet hoes about 9 inches $(225 \mathrm{~mm})$ long were attached to a steel pipe about 6 inches $(150 \mathrm{~mm})$ in diameter and $1 / 4$ inch $(6 \mathrm{~mm})$ thick. The front 7 1/2-inch $(190 \mathrm{~mm})$ length of the pipe was tapered to form a pointed cone. Total length of this unit was about $221 / 2$ inches $(572 \mathrm{~mm}$ ).
During operation, the hoes cut through the depositional crust near the bottom of the furrow on both sides. The total width of the crust breaker's cut was about 24 inches (610 $\mathrm{mm}$ ). The shape of the crust breaker is such that it tends to firm the furrow bottom and reduce infiltration through it, an arrangement that may enhance the intake of water through the sides and into the bed.

\section{Field experiments}

On the UC Davis campus, we divided an area about 321 feet by 200 feet $(98 \mathrm{~m}$ by $61 \mathrm{~m}$ ) on a Yolo loam soil (Typic Xerorthents) into four blocks (main plots) of about 79 feet by 200 feet $(24 \mathrm{~m}$ by $61 \mathrm{~m})$ each: This was used for field tests during the 1991 and 1992 growing seasons. Each main plot was further divided into two subplots. The furrows in one of these subplots were assigned to the crust-breaking action of the torpedo-shaped winged cultivator (the cultivated subplot), while the furrows in the other subplot were left undisturbed (the uncultivated subplot).

Gated pipes were used to irrigate the field. Four subplots were fed by one valve and the other four subplots were fed by a second valve. A flow meter was used to measure the output of each valve. Each subplot had seven tomato beds and eight furrows. Three

\begin{tabular}{|c|c|c|c|c|c|c|c|c|c|c|c|}
\hline \multirow[b]{2}{*}{ Date* } & \multicolumn{2}{|c|}{ Plot 1} & \multicolumn{2}{|c|}{ Plot 2} & \multicolumn{2}{|c|}{ Plot 3} & \multicolumn{2}{|c|}{ Plot 4} & \multicolumn{2}{|c|}{ Plot mean } & \multirow[t]{2}{*}{ Increase } \\
\hline & $\mathrm{C}+$ & $u_{t}$ & C & u & c & U & c & U & c & U & \\
\hline & \multicolumn{10}{|c|}{.L Lmin } & $\%$ \\
\hline $6 / 16$ & $5.87 \ddagger$ & 3.71 & 5.56 & 4.50 & 5.94 & 3.56 & 6.36 & 4.77 & 5.9 & 4.13 & 43.4 \\
\hline $7 / 21$ & 7.95 & 6.74 & 8.63 & 6.56 & 9.58 & 6.13 & 9.95 & 7.57 & 9.0 & 6.78 & 33.6 \\
\hline $8 / 14$ & 5.60 & 4.69 & 5.90 & 4.39 & 5.37 & 5.49 & 6.47 & 5.79 & 5.9 & 5.07 & 14.7 \\
\hline $9 / 1$ & 6.21 & 4.88 & 5.90 & 4.92 & 5.79 & 4.77 & 6.28 & 4.35 & 6.0 & 4.73 & 27.9 \\
\hline \multicolumn{3}{|c|}{ Overall mean§ } & & & & & & & 6.70 & 5.19 & 29.6 \\
\hline \multicolumn{3}{|c|}{ Standard deviation } & & & & & & & 1.47 & 1.12 & \\
\hline
\end{tabular}

- An analysis of variance (ANOVA) based on a split-plot design showed that time of irrigation was significant $(P=0.0001)$ - that is, the mean infiltration rate in plots was not the same for all irrigation dates. However, our analysis showed that the four blocks did not differ from each other in infiltration characteristics. $\dagger \mathrm{C}=$ Cultivated with a torpedo-shaped winged, cultivator. $\mathrm{U}=$ Not cultivated.

₹ Each entry is a mean infiltration rate of three furrows within a subplot.

$\S$ The ANOVA based on a split-plot design showed that the subfactor (cultivated versus uncultivated) significantly differed from each other $(P=0.0006)$. However, the interaction between the main factor (block) and subfactor (cultivation) was not significant. furrows in each subplot were randomly chosen for an inflow-outflow study. Four of the eight scheduled irrigations were selected for infiltration measurements. Before each of these four irrigations, the crust breaker was used to break the depositional crusts at the bottom of the furrows in cultivated subplots.

\section{Design evaluated and modified}

We used the results of the field tests conducted during the 1991 growing season to evaluate the design of the crust-breaker device and modify it as necessary. We found a significant increase in infiltration rate ( $18 \%$ to $59 \%$ ) when the depositional crust was broken with a crust breaker. In our first design, cultivator tines attached in a $\mathrm{V}$ shape to the torpedo were located about 3 inches $(75 \mathrm{~mm}$ ) from the bottom of the torpedo. Our field tests indicated that this type of arrangement leads to a smooth channel at the bottom of the furrow, allowing the water to advance down the furrow quickly. This rapid advance reduces the advantage of breaking the depositional crust. In the second year of the study, the crust breaker was slightly modified so that the wing-shaped cultivator tines were at the same level as the bottom of the torpedo.

\section{Mean infiltration rate}

The lowest increase in mean infiltration rate (the ratio of cumulative infiltration to total irrigation time) resulting from cultivating with the crust breaker was $14.7 \%$ for the Aug. 14, 1992, irrigation, and the highest increase $(43.4 \%$ ) occurred for the June 16, 1992, irrigation (table 1). The overall mean increase was $29.6 \%$. An analysis of variance of the infiltration data indicated that the time of irrigation and cultivation influenced infiltration data because of seasonal variability in infiltration and cultivation practice respectively.

The effect of cultivation on increasing infiltration was highly significant $(P<0.0006)$. Thus it is clear that cultivation with the crust breaker is helpful in enhancing infiltration if the water- 
penetration problem is related to the depositional crust at the bottom of the furrow.

It should be noted that the crustbreaking operation requires an average of approximately $0.45 \mathrm{kWh} /$ acre of energy, whereas the savings in irrigation energy requirements owing to reduced losses in transporting the water from the source to the field are approximately $3.4 \mathrm{kWh} /$ acre for the tomato crop in the Central Valley. It is not practical to have a separate crustbreaking operation prior to each irrigation event. However, the crustbreaking operation can easily be combined with other operations, such as field cultivations (normally two to three), sidedressing and/or postemergence herbicide application.

Tomato yield data obtained in each of the subplots were based on two measurements of yield on a bed about 10 feet $(3 \mathrm{~m})$ long. These yields are quite high, ranging from 33 tons / acre to 41 tons/acre, with a mean of 37.5 tons/acre. We did not attempt to correlate the yield data with the crust-management technique (cultivated versus uncultivated), because we did not alter the irrigation practice to account for infiltration differences.

\section{Conclusions}

Based on the results of this study, we reached the following conclusions:

1. A device was successfully developed to break the depositional crust near the bottom of a furrowirrigated tomato crop to enhance infiltration rate.

2. Breaking the crust on the sides of the bed near the bottom of the furrow with a torpedo-shaped crust breaker increased the infiltration significantly in a furrow-irrigated tomato crop in a Yolo loam soil. The average increase was $29.6 \%$.

S.K. Upadhyaya is Professor, J.J. Far is Visiting Researcher, S. Shafii is Postgraduate Researcher, and H.A. Fattah is Graduate Assistant, all in the Department of Biological and Agricultural Engineering, UC Davis.

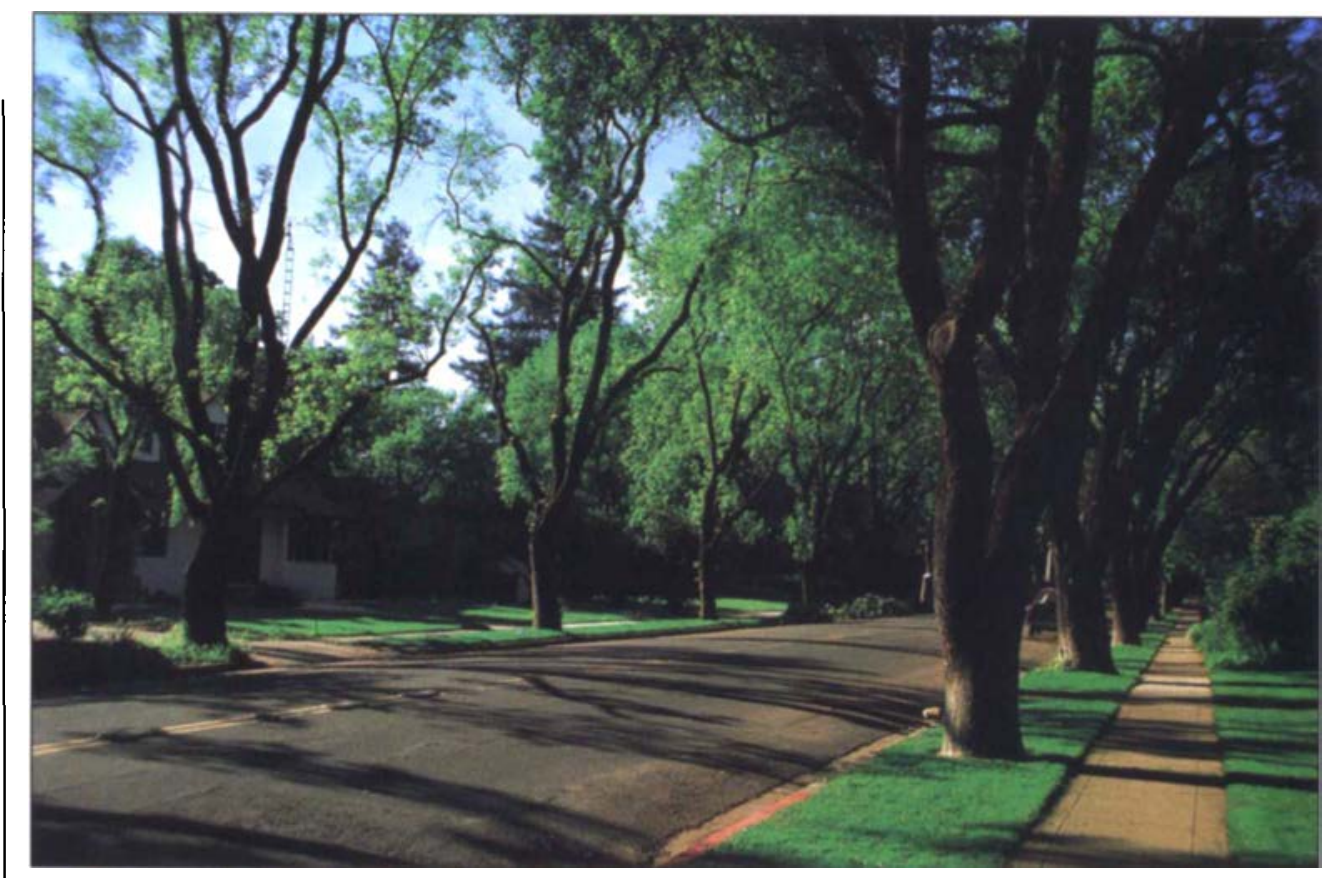

Trees create shade, reduce noise and provide wildlife habitat, as well as make neighborhoods more attractive.

\section{Community programs promote tree care}

Robert Sommer

Trees provide shade, reduce noise and make cities more attractive, among other benefits, but their survival depends on longterm care from humans. A survey of residents in three California cities found that people who planted trees themselves were more satisfied with the outcome than residents whose trees were planted by a city employee or a developer. Residents who participated in an organized planting program were also more likely to receive information on tree maintenance. Overall, $90 \%$ of the program participants received maintenance information, compared with only $16 \%$ of the nonparticipants.

Reduced municipal budgets have had serious consequences for tree-planting and maintenance programs throughout California. Responsibility for trees has shifted from city governments to nonprofit organizations. There are currently 55 local tree-planting organizations affiliated with California ReLeaf, a coordinating group with headquarters in San Francisco. Urban forestry in California relies on partnerships between the private sector, government and these local organizations.

Research has shown that trees make cities more attractive (improve visual aesthetics), raise property values, provide shade (which can lower energy consumption in summer), reduce noise and water runoff and provide wildlife habitat.

Evidence is also accumulating that tree planting can be an important tool in neighborhood and civic revitalization. In turn, the health and survival of city trees require neighborhood action. Forest trees can grow independent of human intervention, but city trees during their early years are almost completely dependent on humans for their 